\title{
SUSCETIBILIDADE DO AMBIENTE A OCORRÊNCIAS DE QUEIMADAS SOB CONDIÇÕES CLIMÁTICAS ATUAIS E DE FUTURO AQUECIMENTO GLOBAL
}

\author{
ANAILTON SALES MÉLO, FLAVIO JUSTINO, CARLOS FERNANDO LEMOS, \\ GILBERTO SEDIYAMA, GUIDO RIBEIRO
}

\author{
Universidade Federal de Viçosa (UFV), Viçosa, MG, Brasil
}

tonsalo@gmail.com,fjustino@ufv.br, cflemos@hotmail.com, g.sediyama@ufv.br, gribeiro@ufv.br

Recebido Março 2009 - Aceito Outubro 2010

\begin{abstract}
RESUMO
As queimadas, a nível global, são a segunda maior fonte de emissões de gases de efeito estufa. Um passo importante para a redução dos impactos das queimadas é por meio de investigação da suscetibilidade, que um determinado ambiente possui para a queima ou mesmo para o alastramento do fogo (risco de fogo). Diante da necessidade de se conhecer possíveis implicações das mudanças na circulação atmosférica em um futuro próximo, pretende-se neste trabalho investigar a suscetibilidade do ambiente à ocorrência de queimadas, baseado no índice de risco de queimadas, a saber: o Índice de Haines (IH). Para tanto, dados de modelagem numérica do modelo ECHAM5/MPI-OM, e dados das reanálises do NCEP são empregados para os cálculos do IH em dois períodos: atual (1980-2000) e projeções climáticas para o final do século (2080-2100). Com base nos resultados, concluiu-se que o modelo de risco de fogo reproduz bem as áreas com maior incidência de queimadas sob condições atuais, e que sob condições de aquecimento global detectou-se um aumento na área de risco em especial para a região Amazônica.
\end{abstract}

Palavras chave: risco de queimadas, climatologia, mudanças climáticas, aquecimento global.

\begin{abstract}
ENVIRONMENTAL SUSCEPTIBILITY FOR THE OCCURANCE OF VEGETACION BURNING UNDER PRESENT DAY AND FUTURE CLOBAL WARMING CONDITIONS.

Vegetation burning is the second source of greenhouse gas emissions into the atmosphere. An important step to reduce the climate impact of these emissions is to investigate the atmospheric susceptibility of a region for fire development (fire risk). This study aims to investigate the environmental susceptibility to fire development, based on the burning risk index: the Haines Index (HI). The study is carried out with data from the ECHAM5/MPI-OM climate model and the NCEP reanalysis data, to calculate the HI during two periods: present day (1980-2000) and climate projections for the end of the $21^{\text {st }}$ century (2080-2100). Based upon the results, we concluded that the Haines index could reproduce properly the areas with the highest fire incidence under present conditions. Moreover, it has been found an enlargement in the fire risk area under global warming conditions, in particular for the Amazon region.

Keywords: risk of fire, climate, climate change, global warming.
\end{abstract}

\section{INTRODUCÃO}

Há tempos os povos têm percebido a estreita relação entre o homem e o clima devido à influência das variações climáticas no bem-estar social. Com o incremento das necessidades de consumo associadas ao aumento da população nos últimos 10.000 anos, cresceram as atividades agropecuárias.

As atividades agrícolas, por sua vez, necessitam de um manejo sazonal do solo, o que envolve na maior parte dos casos o uso do fogo. De acordo com Laturner e Scherer (2004), na história evolutiva do homem, este utiliza o fogo desde as mais remotas eras. Nas últimas décadas tem crescido a preocupação de vários setores da sociedade com o uso indiscriminado do fogo. A queima de biomassa nos ecossistemas devido à expansão da fronteira agrícola, à conversão de florestas e cerrados em pastagens, e à renovação de cultivos agrícolas, são alguns dos fatores mais importantes que causam impactos sobre o clima e a biodiversidade (Kirchoff, 1997; Costa et al., 2007). 
As queimadas ainda provocam o empobrecimento do solo, a destruição da vegetação, problemas de erosão, e estão ligadas a alterações na composição química da atmosfera (Crutzen e Andraea, 1990). Queimadas e incêndios florestais nem sempre têm sido atribuídos diretamente à ação humana. A ocorrência do fogo depende de alguns fatores que permitem o início da reação da combustão, e a sua continuação depende principalmente da energia potencial armazenada no material combustível (Ribeiro e Soares, 1998). Por exemplo, estudos palinológicos na região central do cerrado brasileiro indicam a presença de carvão em reconstruções que datam de 32.000 anos antes do presente (AP) (Ferraz-Vicentini, 1999; SalgadoLabouriau e Ferraz-Vicentini, 1994).

Este período, que está compreendido na última era glacial, que se estende de 100.000 a 10.000 anos AP, caracteriza-se por um clima mais frio e seco em relação ao atual (Justino,2004; Cruz et al., 2005). Todavia, muito pouco é sabido sobre as causas que levaram as condições suscetíveis ao fogo neste período. Acredita-se que a causa mais provável para estas queimadas glaciais foi à incidência de relâmpagos/raios.

$\mathrm{Na}$ região Amazônica, a presença de fragmentos de carvão vegetal em solos de florestas pluviais tem sido estudada por vários autores ao longo dos últimos 15 anos (Sanford et al.,1985; Saldarriaga e West,1986). As datações apresentam idades entre 250 a 6500 anos antes do presente (AP), o que indica a presença de fogo neste período.

As condições ambientais pós-queimadas reforçam os comportamentos que favorecem o surgimento de novas queimadas (Ribeiro e Bonfim, 2000). As árvores removidas no desmatamento na maioria das vezes são de grande porte. Entre os riscos associados à derrubada de grandes áreas da floresta, destaca-se a modificação de agentes do ciclo hidrológico, como a redução da evapotranspiração (Cook e Vizy, 2008) e, conseqüentemente, a re-alimentação do vapor da água atmosférico, podendo assim reduzir a precipitação (Costa e Foley, 2000).

Os impactos das queimadas são destacados em questões que envolvem as mudanças climáticas futuras, sobretudo na intensificação do Aquecimento Global (AG). A queima de biomassa desempenha um papel importante nas emissões globais de carbono e outros gases-traços (Andreae et al., 1996a,b; Crutzen e Andreae, 1990). Acredita-se que as queimadas, a nível global, seja a segunda maior fonte de emissões de gases de efeito estufa. Por exemplo, a quantidade de dióxido de carbono $\left(\mathrm{CO}_{2}\right)$ liberada nas queimadas da Indonésia nos anos de 1997 e 1998 foi equivalente a 25\% do total emitido anualmente devido à queima de combustíveis fósseis (Page et al., 2002). No Brasil, as queimadas são responsáveis por cerca de $60-70 \%$ das emissões de $\mathrm{CO}_{2}$ para a atmosfera, ou seja, é a principal fonte emissora.
Diversos índices têm sido utilizados para a investigação da suscetibilidade atmosférica a ocorrências de queimadas. No Brasil, os mais utilizados são: índice de Angstron, índice Logarítmico do Telicyn, índice de Setzer ou CPTEC, índice de Nesterov, fórmula de Monte Alegre e a fórmula de Monte Alegre Alterada (FMA+). Atualmente, a maior incidência de queimadas no Brasil ocorre no período compreendido entre agosto e novembro com um máximo em setembro (Sismanoglu et al., 2002; Justino et al., 2002). Este máximo sazonal está diretamente associado com o período seco que antecede a estação chuvosa e de plantio.

Diante do exposto acima, neste trabalho se avalia as condições atmosféricas favoráveis a ocorrências de fogo baseado no índice de Haines (IH). O IH tem sido amplamente utilizado na América do Norte e Austrália, todavia, não tem sido empregado no Brasil. Lemos (2006) fez uma avaliação deste índice, onde identificou e verificou que as áreas com maiores incidências de focos de calor mostraram consideráveis correlações com os máximos valores no IH.

\section{DADOS UTILIZADOS}

\subsection{Reanálises do NCEP/NCAR}

Em 1991 teve início o Projeto Reanálise, no qual procurou-se organizar 50 anos de dados do NCEP/NCAR (National Centers for Environmental Prediction/National Center for Atmospheric Research). O principal objetivo era organizar de forma sistemática os dados meteorológicos, possibilitando uma base de informação ágil para pesquisa e monitoramento do clima (Kalnay et al., 1996). A assimilação e reanálises de dados são hoje um processo corrente, que consiste na coleta de dados de observação em diferentes pontos do globo, os quais são posteriormente inseridos em um Modelo de Circulação Geral Atmosférico (MGCA) em modo de prognóstico, ou numa combinação entre modelos atmosféricos e estatísticos.

Neste estudo, as análises são produzidas a partir da climatologia de 20 anos para o período de janeiro de 1980 a dezembro de 2000, a partir das reanálises do NCEP/NCAR. A confiabilidade destes dados para o Hemisfério Sul (HS) melhora significativamente a partir de 1979, beneficiando-se da assimilação de dados de satélite, que complementam parcialmente a escassez de observações convencionais (Hines et al., 2000)

\subsection{Descrição do modelo ECHAM5/MPI-OM}

O segundo conjunto de dados utilizado neste estudo é proveniente de simulações numéricas para o período atual e para um cenário de Aquecimento Global (AG). Para tal fim será utilizada a sexta geração do modelo acoplado ECHAM5/MPI- 
OM, desenvolvido no Instituto Max-Planck de Meteorologia (MPIM) de Hamburgo na Alemanha. Os dois componentes do modelo, a saber: o ECHAM5 para a atmosfera, e o MPI-OM para o oceano estão bem documentados (Jungclaus et al.,2006). Nesse contexto, menciona-se que a configuração usada nesse estudo tem truncamento triangular no número de onda T63, aproximadamente $1,8^{\circ}$ de latitude e de longitude, o que representa uma resolução espacial de aproximadamente $180 \mathrm{x}$ $180 \mathrm{Km}$, na faixa equatorial, com 31 níveis verticais. O modelo oceânico do Instituto Max Planck (MPI-OM) (Marsland et al., 2003) emprega as equações primitivas para um fluído hidrostático com uma superfície livre. A discretização possui 40 níveis verticais com uma resolução horizontal de $1,5^{\circ}$.

O cenário econômico proposto baseia-se no cenário A1B. Esse cenário climático projeta uma descrição de um estado futuro de emissões dos principais gases estufa e aerossóis. Para o cenário intermediário $\mathrm{A} 1 \mathrm{~B}$, a concentração atmosférica de $\mathrm{CO}_{2}$ apresenta 775 ppmv (partes por milhão em volume) para o final do século XXI. Vera et al. (2006), usando vários modelos do IPCC, a partir de projeções futuras para o período de 2070-2099 do cenário A1B, aponta para um aumento da precipitação sobre a América do Sul (AS) subtropical durante o verão, redução de precipitação durante o inverno em quase todo o continente e uma redução da precipitação durante as quatro estações ao longo do ano na região sul dos Andes. Desta forma, pode-se argumentar que se permanecer as condições socioeconômicas propostas, o cenário climático futuro pode ser favorável a uma maior flamabilidade do ambiente devido a maiores períodos de estiagem.

\subsection{Comportamento climático}

O Brasil apresenta vasta dimensão continental e possui diferentes regimes de temperatura e precipitação, devido às características sinóticas e dinâmicas associadas com sistemas atmosféricos que atuam sobre a America do Sul (AS) (Grimm e Natori, 2006). Desta forma, assume-se que os ciclos anuais podem ser tratados como termos harmônicos através dos anos, dentro de um determinado período. Para um diagnóstico de quais variáveis climáticas são determinantes e quais regiões são mais vulneráveis às queimadas, é fundamental a análise do ciclo sazonal de temperatura (Temp), precipitação (Prec) e umidade relativa (UR), a partir de dados observados e/ou dados provenientes de simulações numéricas.

Resultados científicos provenientes de simulações numéricas de clima necessitam de validações em relação aos padrões observados. Com este objetivo, as Figuras 1a-f mostram a distribuição espacial de temperatura do ar, precipitação e umidade relativa, provenientes de reanálises do NCEP e dos dados do modelo ECHAM5/MPI-OM, no período de junho a outubro entre os anos de 1980 a 2000. É durante os meses de junho a outubro que se detecta o maior número de queimadas no Brasil.

Nota-se que de acordo com a ura 1a para as reanálises do NCEP, as regiões com maiores temperaturas são: Mato Grosso, Tocantins, Rondônia, Mato Grosso do Sul e Goiás. Este comportamento também é verificado a partir dos dados do ECHAM5 (Figura 1b). Os dados do ECHAM5, todavia, diferem dos dados de NCEP, pois o modelo apresenta temperaturas mais altas em até $5^{\circ} \mathrm{C}$ em relação aos dados do NCEP. Comparando-se as Figuras 2a-b, observa-se que o ECHAM5 mostra ainda uma área com altos valores de temperaturas entre o Pará e o Amazonas, não existente nas reanálises. É importante notar que ao longo da região costeira e sudeste do Brasil, onde existe maior densidade de dados observados, o modelo e as reanálises apresentam maior similaridade.

A distribuição espacial do campo de precipitação a partir dos dados do NCEP é apresentada nas Figuras 1c-d. Observa-se que com exceção da região sul e o noroeste da região norte, as precipitações são da ordem de $4 \mathrm{~mm} /$ dia para ambos os dados (reanálise e modelo). Na região que se estende desde o oeste do Amazonas em direção a região sudeste, observa-se que os dados do ECHAM5, apresentam maiores valores de precipitação em comparação as reanálises devido a uma melhor reprodução da Zona de Convergência do Atlântico Sul (ZCAS). Embora esta tenha sua atividade enfraquecida nesta época do ano. Os dados apresentam padrões espaciais similares para o nordeste brasileiro (NEB), região sul e noroeste do Brasil.

Análise similar para a umidade relativa mostra que de acordo com as reanálises do NCEP, as regiões com menores valores de umidade relativa são o centro-sul do Mato Grosso e a faixa oeste do Mato Grosso do Sul (Figura 1e). Em contrapartida, os resultados do ECHAM5 mostram os menores valores de umidade relativa sobre o centro-norte do Mato Grosso, centro-sul do estado do Pará e parte do Tocantins (Figura 2f). Nas demais áreas ambos os conjuntos de dados mostram considerável semelhança, em particular na região sul do Brasil. Em linhas gerais, verificou-se que o clima modelado pelo ECHAM5 é mais quente, apresenta maiores índices pluviométricos e menores valores de umidade relativa, quando comparado as reanálises do NCEP.

A segunda comparação entre os dados simulados e os dados provenientes do NCEP é feita usando análise harmônica. A análise harmônica tem sido uma ferramenta útil no estudo dos padrões de elementos meteorológicos, representando as variações de uma série temporal como base de funções periódicas de senos e cossenos (Aslan e Topcu, 1994). Estas funções apresentam freqüências como múltiplos de uma freqüência fundamental. Segundo Wilks (1995), uma dada série 

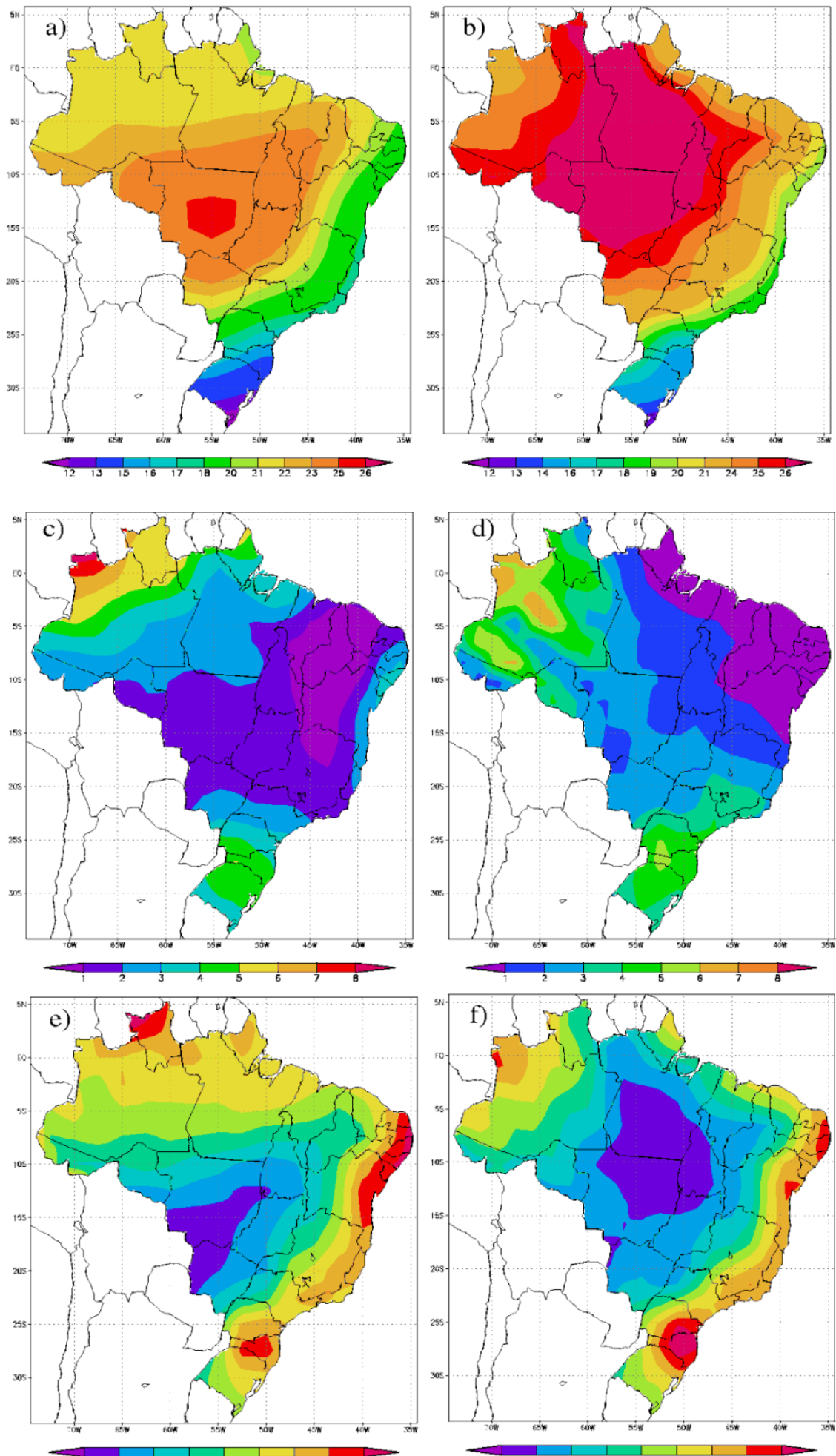

Figura 1 - Climatologia no período de junho a outubro, média dos anos 1980 a 2000, Reanálises (NCEP): a) Temperatura $\left({ }^{\circ} \mathrm{C}\right)$, c), Precipitação (mm/dia), e) UR. Simulações (ECHAM5): b) Temperatura $\left.\left({ }^{\circ} \mathrm{C}\right), \mathrm{d}\right)$ Precipitação (mm/dia), f) UR. 
temporal de dados de amostras eqüidistantes de uma variável, pode ser representada por uma função harmônica:

$$
\mathrm{y}_{\mathrm{t}}=\overline{\mathrm{y}}+\sum_{\mathrm{j}=1}^{\mathrm{N}} \mathrm{C}_{\mathrm{j}} \cos \left(\omega_{\mathrm{j}} \mathrm{t}-\varphi_{\mathrm{j}}\right)
$$

Em que: $\overline{\mathrm{y}}=$ média dos valores da série, $\mathrm{N}=$ número de observações, $C_{j}=$ amplitude; $\omega_{j}=$ freqüência e $\phi_{j}=$ ângulo de fase.

É possível escrever a equação anterior utilizando a função seno. No entanto, a função cosseno é geralmente utilizada, pois o ângulo de fase $(\phi)$ pode ser facilmente determinado como correspondendo ao tempo onde a função harmônica é maximizada:

$$
\mathrm{t}=\frac{\phi_{\mathrm{j}} \mathrm{N}}{2 \pi}
$$

As equações para os cálculos da amplitude dos harmônicos segundo (Emery e Thompson, 1997) são:

$$
\text { - Amplitude }\left(\mathrm{C}_{\mathrm{j}}\right): \mathrm{C}_{\mathrm{j}}=\sqrt{\mathrm{A}_{\mathrm{j}}^{2}+\mathrm{B}_{\mathrm{j}}^{2}}
$$

Tem-se: $\mathrm{A}_{\mathrm{j}}=$ coeficiente do cosseno; $\mathrm{B}_{\mathrm{j}}=$ coeficiente do seno e $\mathrm{C}_{\mathrm{j}}=$ vetor amplitude.

Os termos $A_{j}$ e $B_{j}$ são obtidos pelas seguintes fórmulas:

$$
A_{j}=\frac{2}{N} \sum_{t=1}^{N} y_{t} \cos \left(\frac{2 \pi t}{N}\right) \text { e } B_{j}=\frac{2}{N} \sum_{t=1}^{N} y_{t} \operatorname{sen}\left(\frac{2 \pi t}{N}\right)
$$

- Fase $(\phi)$

O ângulo de fase $(\phi)$ é calculado a partir de uma das equações seguintes, dependendo do valor obtido para $\left(A_{j}\right)$ :

$$
\phi_{j}= \begin{cases}\tan ^{-1} \frac{\mathrm{B}_{\mathrm{j}}}{\mathrm{A}_{\mathrm{j}}} & \mathrm{A}_{\mathrm{j}}>0 \\ \tan ^{-1} \frac{\mathrm{B}_{\mathrm{j}}}{\mathrm{A}_{\mathrm{j}}} \pm \pi \text { ou } \pm 180^{\circ} & \mathrm{A}_{\mathrm{j}}<0 \\ \frac{\pi}{2} \text { ou } 90^{\circ} & \mathrm{A}_{\mathrm{j}}=0\end{cases}
$$

A contribuição de cada harmônico $(j)$ na variância total da série de dados é calculada a partir da razão entre a amplitude do harmônico e duas vezes a variância populacional (Panofsky e Brier, 1969):

$$
j=\frac{C_{j}^{2}}{2 s^{2}}
$$

A análise harmônica tem sido utilizada em vários estudos, com os mais diferentes propósitos. Conforme discutido por Azzali e Menetti (2001), este tipo de analise é útil para caracterizar diferentes regimes climáticos em regiões de transição bem como classificar as zonas climáticas. A vantagem de utilizar esta abordagem matemática está associada à possibilidade de identificar qual o padrão do clima dominante, nas escalas espacial e temporal. Desta forma, pode-se demonstrar as principais características relacionadas com a sazonalidade e, em particular, por exemplo, investigar como estes padrões climáticos se correlacionam com as atividades agropecuárias associados à queima de biomassa e ao risco de fogo.

Os resultados baseados em análise harmônica expressam o comportamento de uma variável em função de sua periodicidade, amplitude e fase (período que ocorre o pico na amplitude). Neste processo, objetiva-se examinar como o componente climático contribui e interage para produzir o ciclo mais representativo dos dados observados e modelados. $\mathrm{O}$ comportamento harmônico da temperatura observada e modelada é mostrado na Figuras 2a-b, para a precipitação na Figuras $2 \mathrm{c}-\mathrm{d}$ e para a umidade relativa na Figuras 2e-f.

As amplitudes de temperatura mostrada nas Figuras 2a-b ilustram que em geral existem pequenas variações zonais. Em ambos os conjuntos de dados a parte sul do Brasil é a que apresenta as maiores variações sazonais de temperatura, por possuir uma melhor definição das estações do ano. De acordo com os resultados propostos pelo modelo ECHAM5, sobre a parte norte do Mato Grosso e grande parte do Pará há uma variação sazonal significativa de temperatura com valores que podem chegar a $4^{\circ} \mathrm{C}$.

As áreas com maiores amplitudes de precipitação demonstram uma grande distinção entre as estações chuvosa e seca. Na Figura 2c destacam-se os estados do Acre, Amapá, Pará, Mato Grosso, Goiás, Tocantins, Bahia e Maranhão, com amplitudes entre $4 \mathrm{~mm}-6 \mathrm{~mm}$. A Figura $2 \mathrm{~d}$, mostra com base nos dados de ECHAM5 os maiores valores de amplitudes desde o sul da região norte, até o nordeste, e nos estados de Mato Grosso, Goiás, e Tocantins, com valores entre $4 \mathrm{~mm} /$ dia a $6 \mathrm{~mm} / \mathrm{dia}$

É importante notar que os dados de ECHAM5 apresentam o estado do Pará como tendo as maiores variações sazonais da umidade relativa (Figura 2f), característica não notada nos dados do NCEP (Figura 3e). Maiores valores na amplitude mostram uma alta flutuabilidade entre os períodos quentes e secos, e os períodos frios e úmidos. Como será discutido adiante, áreas de alta amplitude podem se caracterizar como zonas propícias as queimadas.

\section{MODELO DE RISCO DE QUEIMADA: ÍNDICE DE HAINES ( IH )}

As análises são feitas a partir do índice de baixa severidade atmosférica, o Índice de Haines (IH), tendo como 

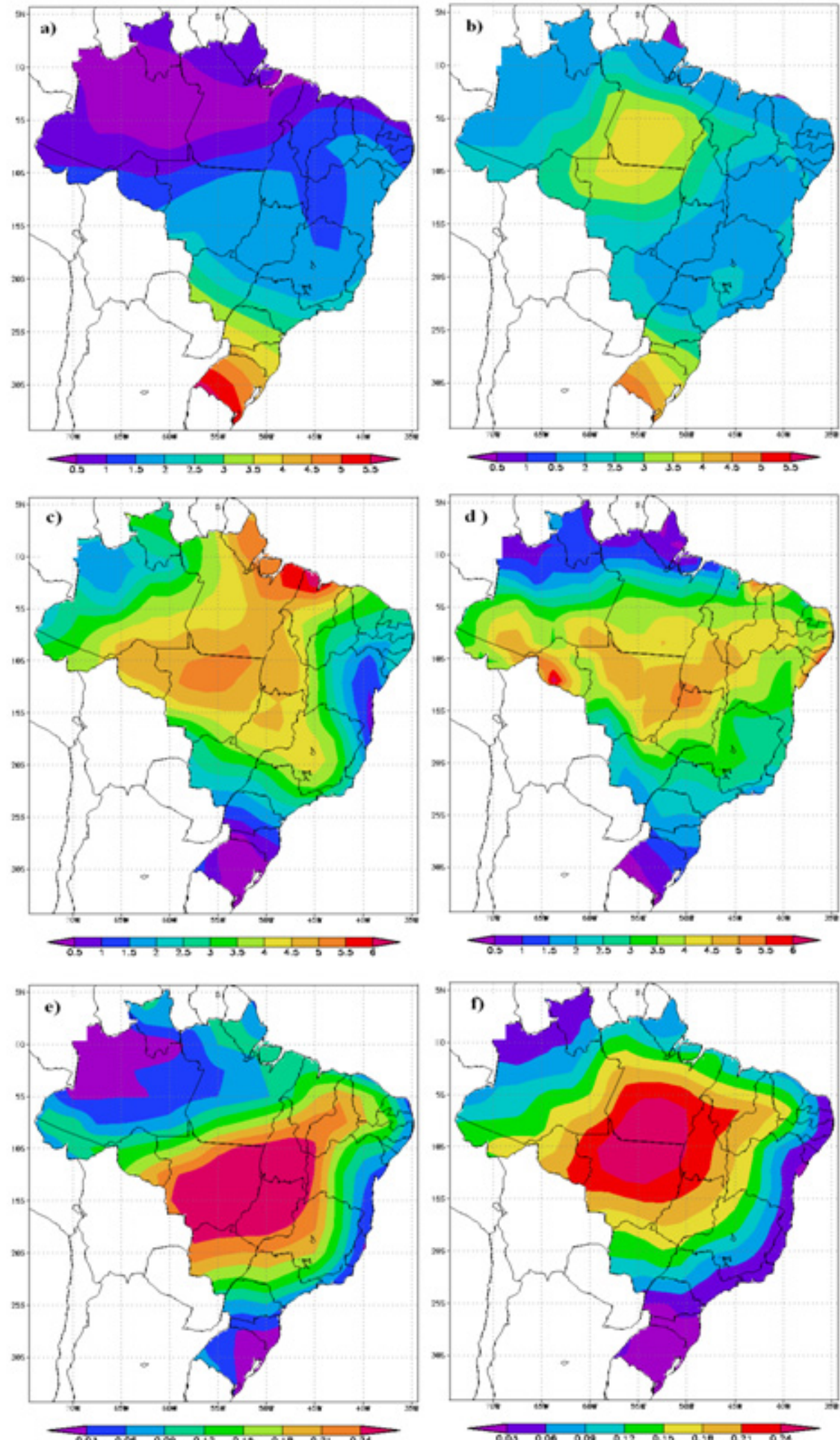

Figura 2 - Primeiro harmônico de junho a outubro, média dos anos 1980 a 2000. Reanálises da Amplitude (NCEP): a) Temperatura c) Precipitação, e) UR (\%) Simulações da Amplitude (ECHAM5): b) Temperatura d) Precipitação, f) UR (\%). 
Tabela 1 - Cálculo do Índice de Haines $(\mathrm{IH})$, baseado nas diferenças de temperatura $(\mathrm{T}=$ temperatura do ar e $\mathrm{Td}=$ temperatura do ponto de orvalho) de acordo com a altitude. Fonte: Winkler et al. (2005)

\begin{tabular}{|c|c|c|c|c|}
\hline \multirow[t]{2}{*}{ Altitude } & \multicolumn{2}{|c|}{ Componente da Estabilidade (A) } & \multicolumn{2}{|c|}{ Componente da Umidade (B) } \\
\hline & Cálculo & Categoria & Cálculo & Categoria \\
\hline $\begin{array}{c}\text { baixa } \\
(\leq 1500 \mathrm{~m})\end{array}$ & $\begin{array}{c}A=T 950 \mathrm{hPa}- \\
T 850 \mathrm{hPa}\end{array}$ & $\begin{array}{l}A=1 \text { se }<4^{\circ} \mathrm{C} \\
A=2 \text { se } 4-7^{\circ} \mathrm{C} \\
A=3 \mathrm{se} \geq 8^{\circ} \mathrm{C}\end{array}$ & $\begin{array}{r}\mathrm{B}=\mathrm{T} 850 \mathrm{hPa}- \\
\mathrm{Td} 850 \mathrm{hPa}\end{array}$ & $\begin{array}{l}B=1 \text { se }<6^{\circ} \mathrm{C} \\
B=2 \text { se } 6-9{ }^{\circ} \mathrm{C} \\
B=3 \text { se } \geq 10^{\circ} \mathrm{C}\end{array}$ \\
\hline $\begin{array}{c}\text { média } \\
(1500-3500 \mathrm{~m})\end{array}$ & $\begin{array}{c}\mathrm{A}=\mathrm{T} 850 \mathrm{hPa}- \\
\mathrm{T} 700 \mathrm{hPa}\end{array}$ & $\begin{array}{l}A=1 \text { se }<6^{\circ} \mathrm{C} \\
A=2 \text { se } 6-10^{\circ} \mathrm{C} \\
A=3 \text { se } \geq 11^{\circ} \mathrm{C}\end{array}$ & $\begin{array}{c}\mathrm{B}=\mathrm{T} 850 \mathrm{hPa}- \\
\mathrm{Td} 850 \mathrm{hPa}\end{array}$ & $\begin{array}{l}B=1 \text { se }<6 \stackrel{\circ}{ }=1 \\
B=2 \text { se } 6-12^{\circ} \mathrm{C} \\
B=3 \text { se } \geq 13^{\circ} \mathrm{C}\end{array}$ \\
\hline $\begin{array}{c}\text { alta } \\
(\geq 3500 \mathrm{~m})\end{array}$ & $\begin{array}{c}\mathrm{A}=\mathrm{T} 700 \mathrm{hPa}- \\
\mathrm{T} 500 \mathrm{hPa}\end{array}$ & $\begin{array}{l}A=1 \text { se }<18^{\circ} C \\
A=2 \text { se } 18-21^{\circ} C \\
A=3 \text { se } \geq 22^{\circ} C\end{array}$ & $\begin{array}{c}\mathrm{B}=\mathrm{T} 700 \mathrm{hPa}- \\
\mathrm{Td} 700 \mathrm{hPa}\end{array}$ & $\begin{array}{l}B=1 \text { se }<15{ }^{\circ} \mathrm{C} \\
B=2 \text { se } 15-20^{\circ} \mathrm{C} \\
B=3 \text { se } \geq 21^{\circ} \mathrm{C}\end{array}$ \\
\hline
\end{tabular}

base a climatologia mensal dos dois períodos. O período atual compreendido entre 1980-2000, e o clima futuro simulado combase no cenário A1B como proposto pelo Painel Intergovernamental para as Mudanças Climáticas (IPCC) entre 2080-2100.

Por vários anos, valores característicos das condições de estabilidade atmosférica e do teor de vapor da água na atmosfera foram observados e relacionados com a propagação de focos de calor (queimadas), em grandes áreas remotas nos Estados Unidos (Brotak e Reifsnyder, 1977). OÍndice de Haines (IH)é um indicador para o desenvolvimento potencial de atividade convectiva de fogo como função da temperatura vertical e dos perfis de umidade do ar calculada na baixa, média e alta atmosfera (Haines,1988).

Recentemente, foram desenvolvidos estudos do IH para o Brasil, no qual verificou-se que a região central do Brasil e a faixa norte do nordeste brasileiro (NEB), são as regiões mais propícias ao desenvolvimento de queimadas de acordo com o Índice de Haines (Lemos, 2006). Matematicamente, o cálculo do Índice de Haines (IH) é definido pela soma do componente da estabilidade (A), e do componente da umidade atmosférica (B), como apresentado na Tabela 1. Assim, $\mathbf{I H}=\mathbf{A}+\mathbf{B}$ : em que, o termo A representa a diferença de temperatura do ar entre dois níveis da atmosfera e o termo $\mathbf{B}$ caracteriza as diferenças entre as temperaturas do ar e as temperaturas do ponto de orvalho para cada nível da atmosfera, ou seja, a depressão do ponto de orvalho.

Tabela 2 - Tipo de risco em função da variação da temperatura baseado no cálculo do $\mathrm{IH}$

\begin{tabular}{cc}
\hline Risco & $\mathrm{IH}$ \\
\hline muito baixo & $\leq 12^{\circ} \mathrm{C}$ \\
baixo & $13^{\circ} \mathrm{C}-22^{\circ} \mathrm{C}$ \\
moderado & $23^{\circ} \mathrm{C}-24^{\circ} \mathrm{C}$ \\
alto & $\geq 24^{\circ} \mathrm{C}$ \\
\hline
\end{tabular}

Nas análises optou-se em apresentar o risco de fogo (IH) em função da temperatura, a saber: índice muito baixo, com valores menores que $12^{\circ} \mathrm{C}$; índice baixo com valores compreendidos entre $13^{\circ} \mathrm{C}$ e $22^{\circ} \mathrm{C}$; índice moderado entre $23^{\circ} \mathrm{C}$ e $24^{\circ} \mathrm{C}$ e índice alto acima de $24^{\circ} \mathrm{C}$, conforme Tabela 2 .

\section{RESULTADOS E DISCUSSÕES}

No que segue são apresentados os comportamentos dos termos A, B e IH para os dados do NCEP e ECHAM5 dos meses de junho, julho, agosto, setembro e outubro, na média atmosfera, devido esta camada representar com mais propriedade as condições atmosféricas favoráveis as queimadas (Lemos, 2006). Deve-se notar que a maior parte das queimadas no Brasil é de origem antrópica, mesmo que o risco de queimadas seja máximo, isto não implica na presença do fogo. $\mathrm{O}$ caso é diferente da América do Norte (AN), onde a maior parte das queimadas é de origem natural. O IH fornece unicamente a favorabilidade atmosférica à ocorrência de incêndios florestais.

\subsection{Análise para o mês de junho}

As Figuras 3a-c e as Figuras 3d-f foram geradas para o mês de junho. Nota-se que na média atmosfera o componente da estabilidade (termo A), do índice de Haines para os dados do NCEP (Figura 3a), apresenta categoria (2), com valores de temperatura entre $6^{\circ} \mathrm{C}-10^{\circ} \mathrm{C}$. O componente da umidade (termo B) (Figura 3b) apresenta categoria (1), com temperaturas menores que $6^{\circ} \mathrm{C}$ na região centro-oeste e no oeste de Minas Gerais. Com base na soma dos termos $\mathrm{A}$ e $\mathrm{B}(\mathrm{A}+\mathrm{B}=\mathrm{IH})$, têm-se valores de temperatura menor que $12^{\circ} \mathrm{C}$ (risco baixo) para a costa brasileira, e valores entre $12^{\circ} \mathrm{C}-20^{\circ} \mathrm{C}$ na maior parte da região centro-oeste do Brasil (Figura 3c), o que caracteriza um risco moderado. 

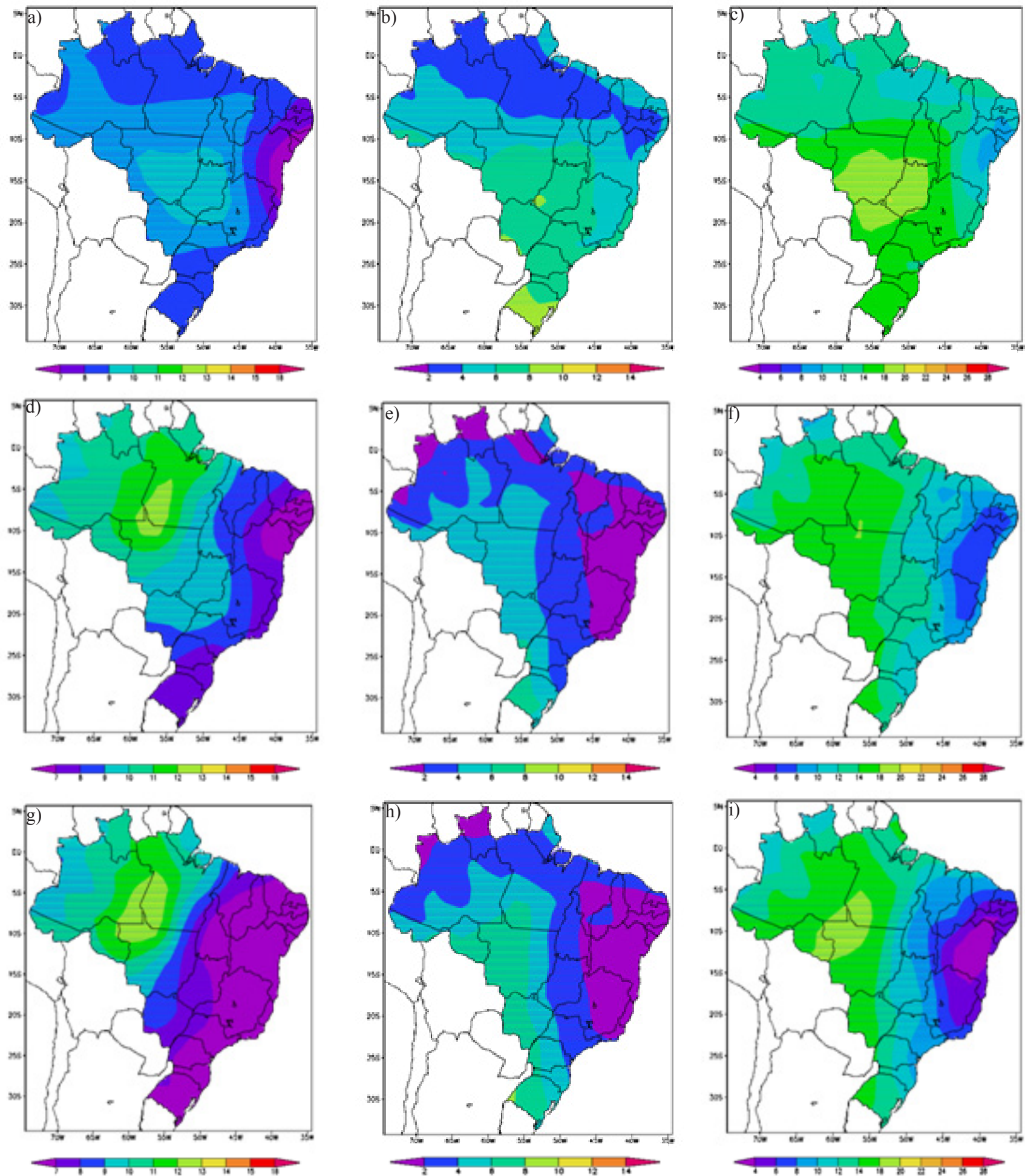

Figura 3 - Suscetibilidade do ambiente a ocorrência de queimadas sob condições atuais a partir dos dados do NCEP no mês de junho: a) Termo A, b) Termo B, c) Índice de Haines. Suscetibilidade do ambiente a ocorrência de queimadas sob condições atuais a partir dos dados do ECHAM no mês de junho: d) Termo A, e) Termo B, f) Índice de Haines. Suscetibilidade do ambiente a ocorrências de queimadas no futuro a partir dos dados do ECHAM no mês de junho: g) Termo A, h) Termo B, i) Índice de Haines. 
As análises para os dados do ECHAM5 mostram que existe maior instabilidade (termo A) na região leste do Pará e oeste da Amazônia (Figura 3d), quando comparado aos resultados do NCEP. O componente da umidade (termo B) por outro lado mostra maior umidade relativa (Figura 3e), com diferenças entre a temperatura do ar e do ponto de orvalho menores que $6^{\circ} \mathrm{C}$. Desta forma, os valores indicados pelo modelo ECHAM5 no mês de junho indicam o risco de incêndios de grande proporção é pequeno (Figura 3f).

Com o objetivo de investigar a favorabilidade atmosférica às queimadas no final do século XXI e sob condições climáticas distintas, as Figuras 3f-h foram geradas com base nas projeções futuras (2080-2100) a partir do modelo ECHAM5. O termo A (Figura 3g) apresenta a categoria (3) na região norte e no estado do Mato Grosso, e categoria (2) para as demais regiões. O termo B (Figura 3h), por outro lado, apresenta a categoria (1) na maior parte do território brasileiro, já que a depressão do ponto de orvalho é menor que $6^{\circ} \mathrm{C}$. Com base nestas análises, não devem ser esperadas mudanças significativas na suscetibilidade atmosférica à ocorrências de queimadas para o final do século. Embora exista uma área de risco moderado na parte oeste do Mato Grosso com base na análise dos dados projetados para o futuro pelo modelo ECHAM5.

Visando uma investigação mais criteriosa, optou-se por apresentar as Figuras 4a-b com os focos de queimadas detectadas pelo satélite NOAA-12, para o mês de junho dos anos 2006 e 2007. A distribuição espacial dos focos de queimadas apresenta pequena variabilidade espacial ao longo dos anos. Portanto, a Figura 4 ilustra as áreas no Brasil com maior risco de fogo e incidência de queimadas, o que indiretamente pode ser interpretado como as áreas de maior risco de fogo.

As queimadas detectadas pelo satélite NOAA-12 atingiram no mês de junho aproximadamente 3.150 focos para o ano de 2006 (Figura 4a), e cerca de 4.900 focos para o ano de 2007 (Figura 4b). As áreas de maior ocorrência de queimadas são as regiões sudeste e centro-oeste do Brasil. Em uma breve avaliação, pode-se notar que estas áreas também apresentam os maiores valores de IH (Figura 3c-f).

\subsection{Análise para o mês de julho}

As análises para o mês de julho, de acordo com os dados do NCEP, mostram que na média atmosfera o termo A (Figura 5a) apresenta categoria (2) para as regiões norte, nordeste, sul, sudeste e Mato Grosso, e categoria (3) para os estados do Mato Grasso do Sul e Tocantins. O termo B (Figura $5 b)$ apresenta categoria (1) para as regiões norte, nordeste e sudeste e nos estados do Paraná e Santa Catarina; categoria (2) para a região centro-oeste e o estado do Rio Grande do Sul. Logo, o índice de Haines (IH) (Figura 5c) caracteriza-se com risco baixo (4) em praticamente todo território brasileiro, exceto para o centro do Mato Grosso e leste de Goiás, onde tem-se risco moderado (5).

A comparação entre os resultados do ECHAM5 e do NCEP mostra uma intensificação de magnitude tanto nos valores do componente da estabilidade (termo A) (Figura 5d), implicando numa atmosfera mais instável, quanto no termo da umidade (termo B) (Figura 5e), o que sugere uma atmosfera mais seca no caso do ECHAM5. Embora, esta intensificação
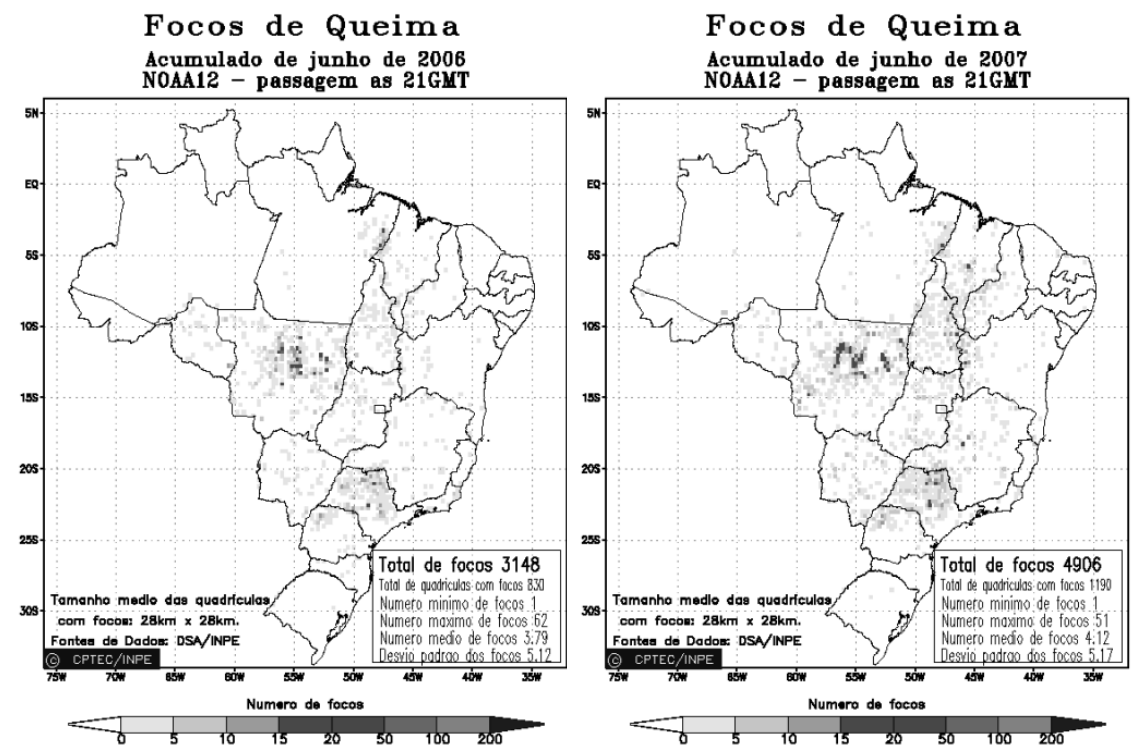

Figura 4 - a) Focos de Queimadas acumuladas do mês de junho de 2006. b) Focos de Queimadas acumuladas do mês de junho de 2007. Fonte: Centro de Previsão de Tempo e Estudos Climáticos (CPTEC). 

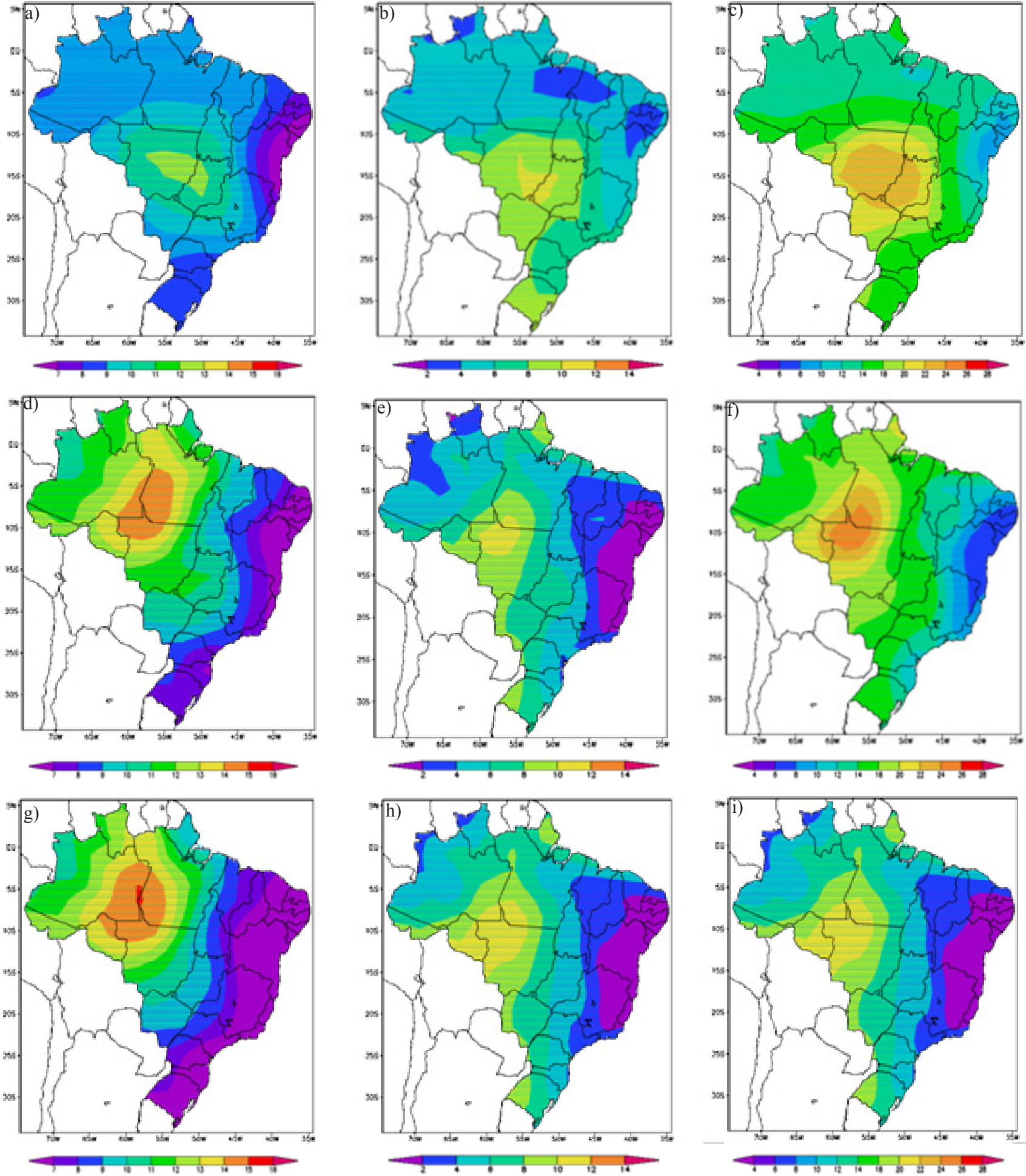

Figura 5 - Suscetibilidade do ambiente a ocorrências de queimadas sob condições atuais a partir dos dados do NCEP para o mês de julho: a) Termo A, b) Termo B, c) Índice de Haines. Suscetibilidade do ambiente a ocorrências de queimadas do presente a partir dos dados do ECHAM para o mês de julho: d) Termo A, e) Termo B, f) Índice de Haines. Suscetibilidade do ambiente a ocorrências de queimadas no futuro a partir dos dados do ECHAM para o mês de julho: g) Termo A, h) Termo B, i) Índice de Haines. 

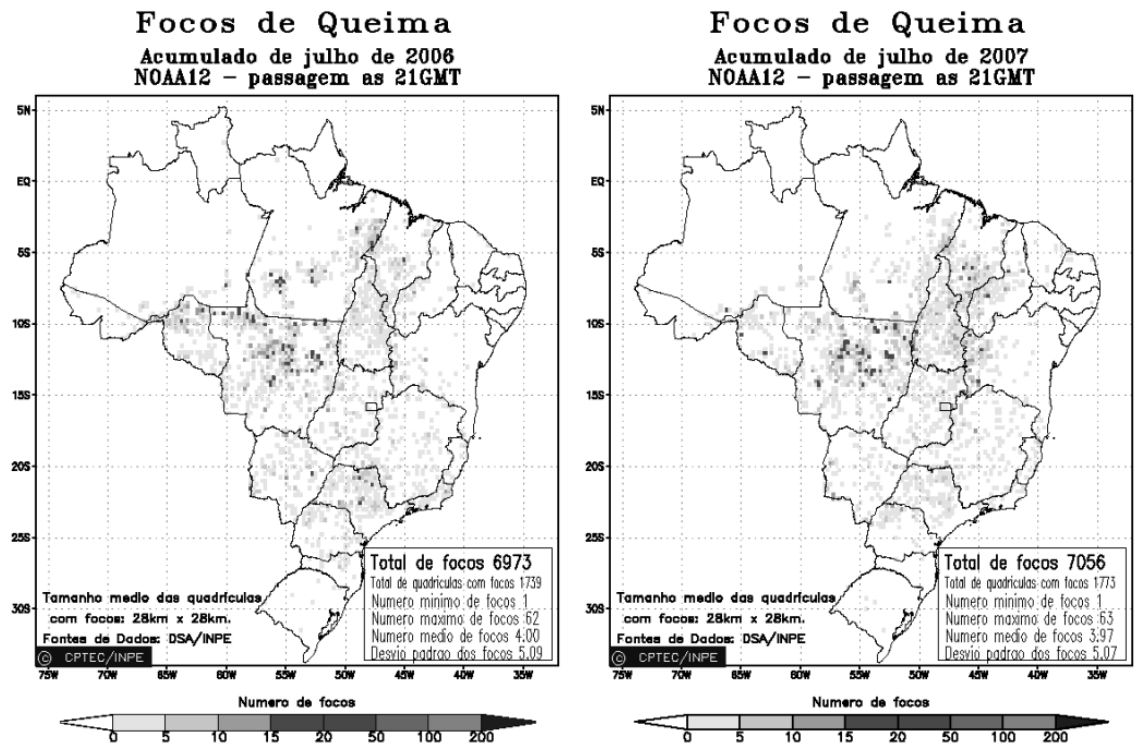

Figura 6 - a) Focos de Queimadas acumuladas do mês de julho de 2006. b) Focos de Queimadas acumuladas do mês de julho de 2007 Fonte: Centro de Previsão de Tempo e Estudos Climáticos (CPTEC).

dos termos A e B não resultam em grandes mudanças no valor final do IH em comparação aos resultados do NCEP. Deve-se notar, que o norte do Mato Grosso e o sul do Pará apresentam um risco de queimadas moderado.

Comparando-se os meses de junho e julho é nítida a intensificação dos valores do $\mathrm{IH}$, assim como um aumento na área de abrangência de risco máximo para o mês de julho. As análises do $\mathrm{IH}$, para o cenário futuro de aquecimento global, apresentam claramente uma intensificação dos termos A e B (Figuras $5 \mathrm{~g}$-i). Isto mostra que toda área, desde o norte do Mato Grosso, oeste do Pará e leste do Amazonas, estará bastante vulnerável ao desenvolvimento de queimadas de grande proporção, a se confirmar as previsões do clima.

Em adição o termo A, que reproduz a estabilidade atmosférica ou o poder convectivo, domina o processo deixando uma contribuição menor para o termo B. Esta intensificação do IH no mês de julho em relação a junho para as duas épocas, é bem acompanhada pelo aumento dos focos de queimadas (Figuras 6a-b). Isto é, apesar das diferenças entre as áreas de risco máximo e a localização dos focos, existe uma boa relação entre ambos, em particular para o IH calculado a partir dos dados do NCEP e os focos de queima.

As queimadas refletem, antes de tudo, uma prática humana que acompanha a sazonalidade natural, seguindo a ocorrência da estiagem na maior parte do país. De acordo com os dados do satélite NOAA-12, em julho de 2007, o número de focos de calor detectados no Brasil foi maior que no mesmo período do ano de 2006: 6.973 (Figura 6a) contra 7.056 (Figura $6 b)$.

\subsection{Análise para o mês de agosto}

Observou-se na média atmosfera para o mês de agosto, que o componente da estabilidade (termo A) para os dados do NCEP (Figura 8a), apresenta categoria (2) para as regiões sul, nordeste e norte da região norte. O sudeste do Amazonas, sul do Pará e a região centro-oeste apresentam categoria (3). O componente da umidade (termo B) (Figura 8b) apresenta categoria (1) na parte norte da região norte e na região nordeste; categoria (2) para as regiões sul, sudeste e centro-oeste, e valores moderados (3) para o centro-sul do Mato Grosso. Com isso, o IH (Figura 8c) apresenta risco alto para a região centro-oeste com temperaturas acima de $24^{\circ} \mathrm{C}$, e risco moderado (5) para as demais regiões.

Os resultados do ECHAM5, quando comparados aos resultados do NCEP, apresentam uma área de maior abrangência do termo A com diferente distribuição espacial de categoria (3), o que sugere uma maior instabilidade atmosférica (Figura 8d). Para o termo B, nota-se que o modelo apresenta um clima mais úmido do que o proposto pelo NCEP, já que a diferença entre a temperatura do ar e a temperatura do ponto de orvalho é menor para o ECHAM5 (Figura 8e). Esta umidade não é suficiente, todavia, para reduzir o risco de queimada na área que se estende desde o Mato Grosso até o Pará (Figura 8f).

Analises para o cenário de aquecimento global (Figuras 8g-i), apresentam uma intensificação substancial das condições favoráveis ao desenvolvimento do fogo. Isto é claramente verificado para os estados do Mato Grosso, Pará e Amazonas (Figura 8i). A avaliação dos meses anteriores (junho, julho) ilustra que com o início do período de estiagem no Brasil central, 
cresce a possibilidade/favorabilidade atmosférica à ocorrência de queimadas. A Figuras 7a-b que mostra a distribuição dos focos de queimadas para o mês de agosto nos anos de 2006 e 2007, ilustra que a região centro-norte do Brasil é a que apresenta o maior número de queimadas. Para o ano de 2006, cerca de 25.800 focos de queimadas foram detectados, já em de 2007 foram detectados cerca de 21.450.

\subsection{Análise para o mês de setembro}

Durante o mês de setembro passa a haver de acordo com os dados do NCEP, uma desintensificação dos termos A e $\mathrm{B}$, e conseqüentemente do índice de Haines, em comparação ao mês de agosto. Embora ainda possa ser observada a área de risco no Brasil central. A análise dos resultados do ECHAM5 (Figuras 9d-f) mostra-se totalmente diferente em termos de espacialização e magnitude, quando comparados aos dados do NCEP (Figuras 9a-c). Enquanto os resultados do NCEP apresentam a região central do Brasil como a mais instável e mais seca, os resultados do ECHAM5 apresentam o Pará e o oeste do nordeste brasileiro (NEB). Esta redução do IH em setembro, quando comparado a agosto não está de acordo com o aumento no número de focos de calor como mostrado pelas Figuras 10a-b e 7a-b. Áreas em que foram identificadas um alto número de queimadas, como Rondônia e leste do Pará, não mostram condições de alto risco de acordo com o IH.

Para um cenário futuro de aquecimento global, o IH apresenta uma intensificação notória do termo A (Figuras 9g-i). Logo, o poder convectivo é responsável por grande parte do processo que resulta no risco de queimadas, enquanto que o teor de vapor d'água na atmosfera no nível de $850 \mathrm{hPa}$ tem uma menor contribuição. Desta forma, grandes áreas localizadas nas regiões centro-oeste e norte podem apresentar uma maior suscetibilidade à queima em um cenário futuro.

Setembro é o mês com maior incidência de queimadas principalmente nos estados do Pará, Tocantins e norte do Mato Grosso. Portanto, os resultados com maior confiabilidade são os resultados do ECHAM5, já que se mostraram numa melhor coerência em relação aos focos de queimadas detectados.

\subsection{Análise para o mês de outubro}

Observou-se para média atmosfera, que o termo A para os dados NCEP (Figura 11a), apresenta categoria (3) na região central do Brasil, e parte do sudeste, com correspondentes valores em temperaturas de $13^{\circ} \mathrm{C}$. $\mathrm{O}$ componente da umidade (termo B) (Figura 11b) apresenta categoria (2), abaixo de $10^{\circ} \mathrm{S}$ de latitude e categoria (1) acima de $10^{\circ} \mathrm{S}$ de latitude. Assim sendo, o IH mostra-se para todo o Brasil com risco baixo (4), com temperaturas menores que $18^{\circ} \mathrm{C}$.

Para os resultados do ECHAM5 (Figuras 11d-f), o componente da estabilidade se mostra mais estável, e a depressão do ponto de orvalho, o termo B, apresenta-se mais úmido implicando que o IH também apresenta-se como risco muito baixo $(2,4)$ e baixo (4). As análises mostram que este mês apresenta pouca favorabilidade à queima. Isto também se verifica para as simulações futuras (2080-2100) (Figuras 11g-i). Isto não é correspondido pelos focos de calor (Figuras 10a-b).
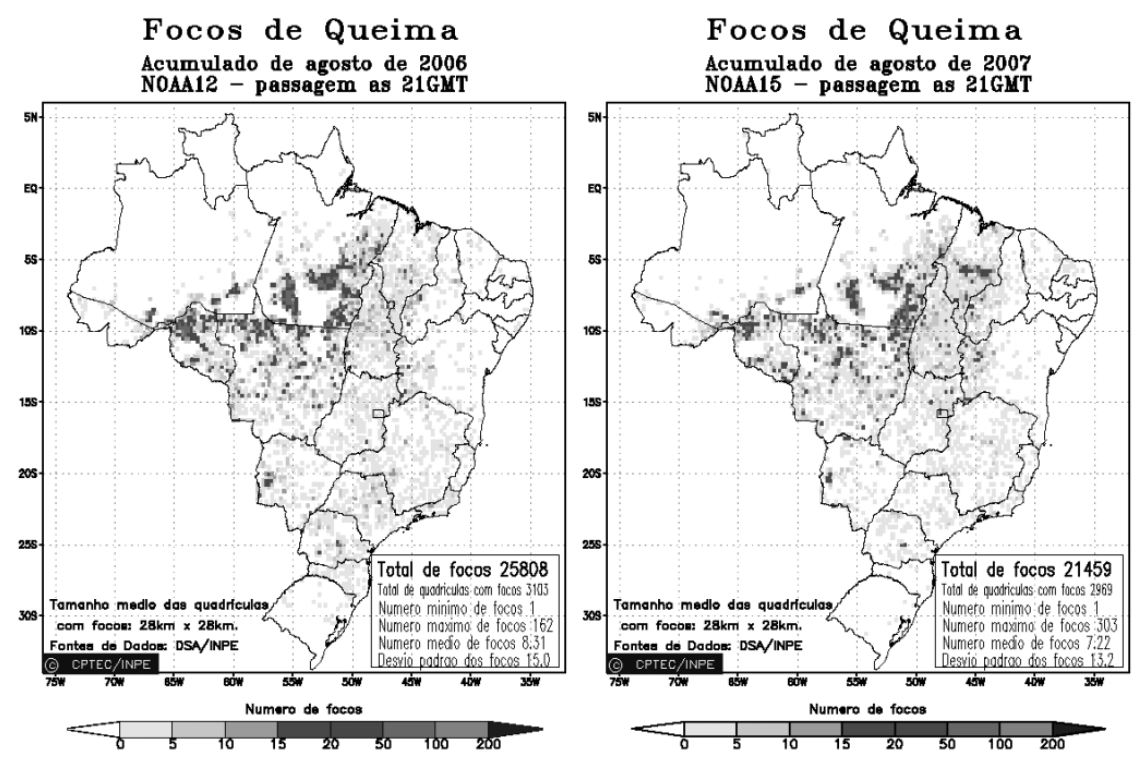

Figura 7 - a) Focos de Queimadas acumuladas do mês de Agosto de 2006. b) Focos de Queimadas acumuladas do mês de Agosto de 2007. Fonte: Centro de Previsão de Tempo e Estudos Climáticos (CPTEC). 

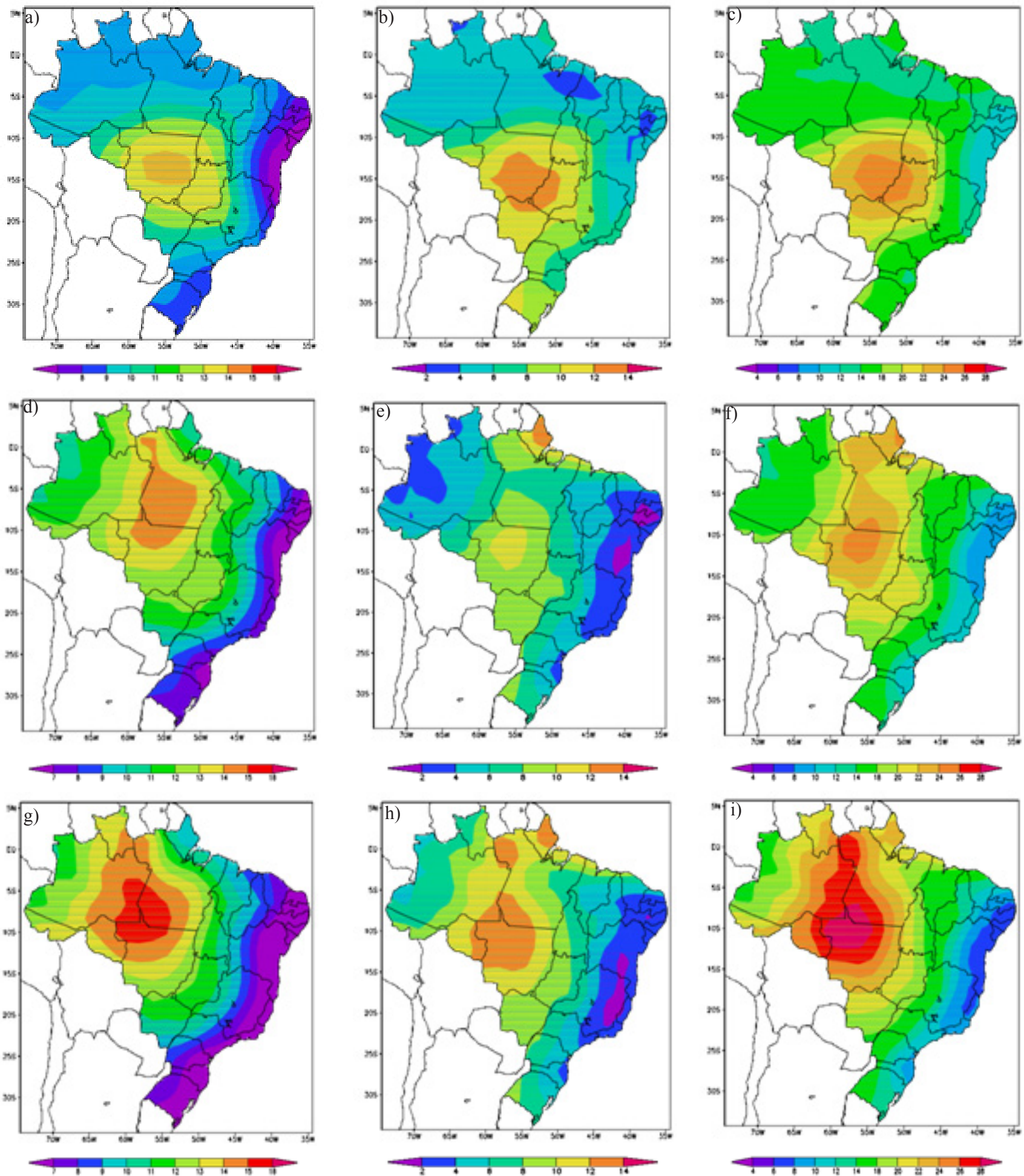

Figura 8 - Suscetibilidade do ambiente a ocorrências de queimadas sob condições atuais do presente a partir dos dados do NCEP para o mês de agosto: a) Termo A, b) Termo B, c) Índice de Haines. Suscetibilidade do ambiente a ocorrências de queimadas sob condições atuais a partir dos dados do ECHAM para o mês de agosto: a) Termo A, b) Termo B, c) Índice de Haines. Suscetibilidade do ambiente a ocorrências de queimadas no futuro a partir dos dados do ECHAM para o mês de agosto: a) Termo A, b) Termo B, c) Índice de Haines. 

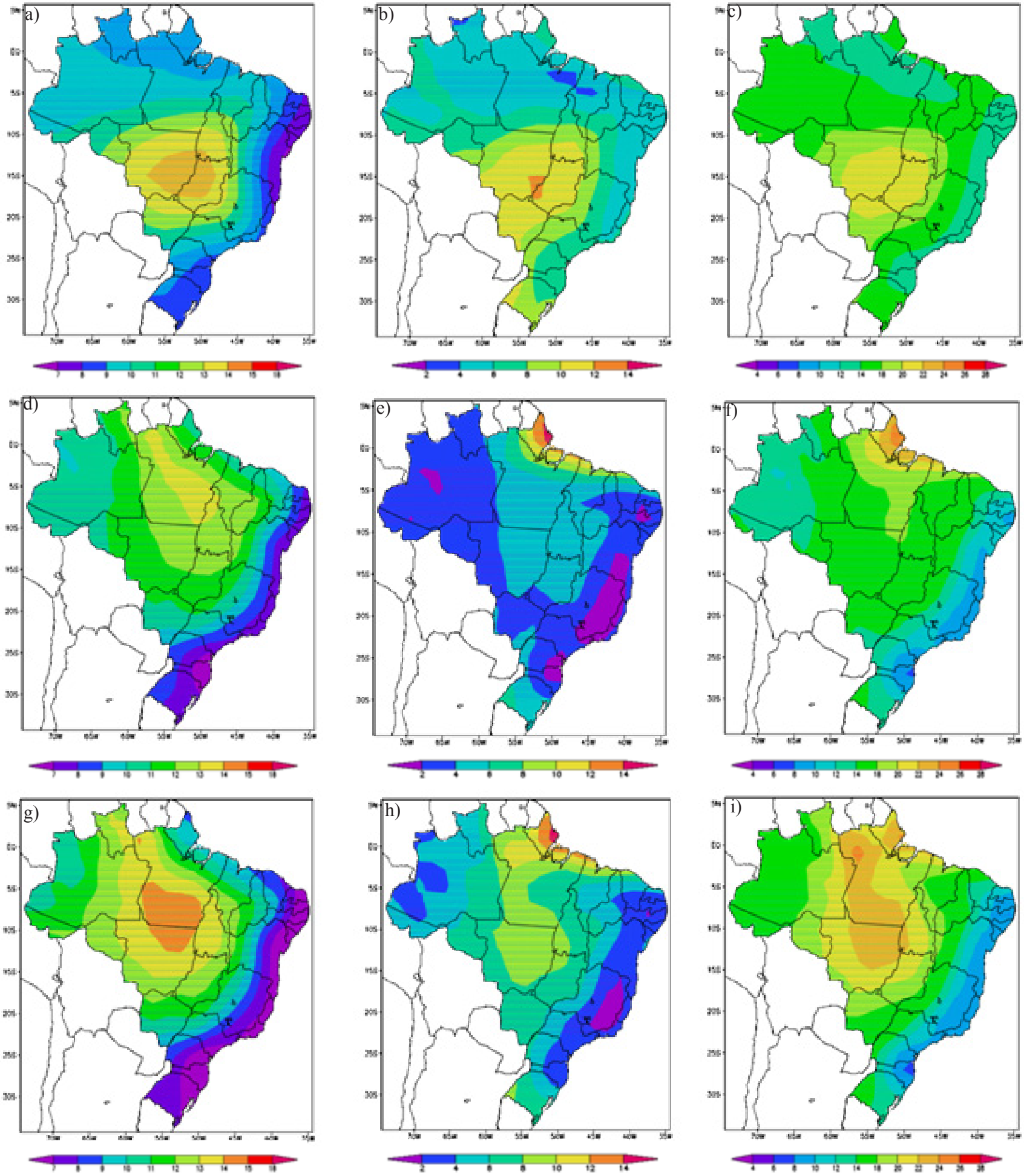

Figura 9 - Suscetibilidade do ambiente a ocorrências de queimadas sob condições atuais a partir dos dados do NCEP para o mês de setembro: a) Termo A, b) Termo B, c) Índice de Haines. Suscetibilidade do ambiente a ocorrências de queimadas sob condições atuais a partir dos dados do ECHAM para o mês de setembro: d) Termo A, e) Termo B, f) Índice de Haines. Suscetibilidade do ambiente a ocorrências de queimadas no futuro a partir dos dados do ECHAM para o mês de setembro: g) Termo A, h) Termo B, i) Índice de Haines. 

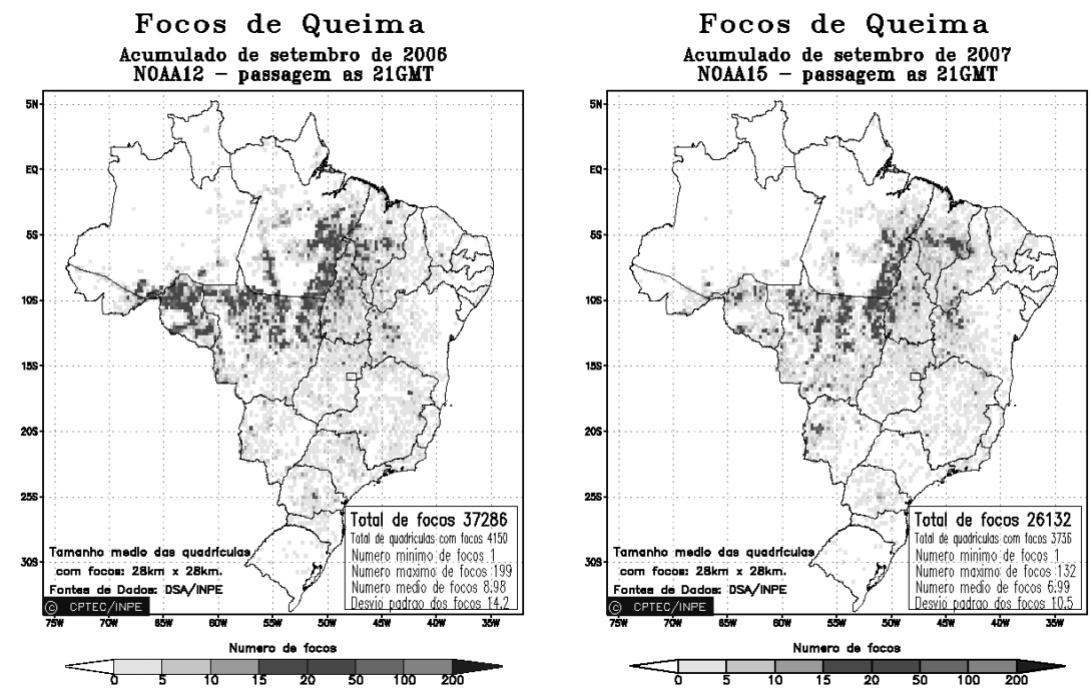

Figura 10 - a) Focos de Queimadas acumuladas do mês de setembro de 2006. b) Focos de Queimadas acumuladas do mês de setembro de 2007 Fonte: Centro de Previsão de Tempo e Estudos Climáticos (CPTEC).

De acordo com a figura, um alto índice de queimadas ainda é verificado no Brasil, principalmente no Pará e Maranhão.

É importante salientar que estes resultados não podem ser entendidos unicamente como uma falha na metodologia do IH, mas sim, como uma possível limitação na representação do clima conforme proposto pelo NCEP, bem como pelo clima modelado pelo ECHAM5. Em adição, as análises mostradas são baseadas em médias mensais, o que pode suavizar a distribuição dos termos A, B e IH. O cálculo em nível diário pode apresentar resultados mais satisfatórios. Outro ponto a se destacar é a baixa resolução espacial dos dados. Lemos (2006), com base em dados diários do modelo ETA, verificou uma boa correlação entre os focos detectados e as áreas de risco máximo.

\section{CONCLUSÕES}

Neste trabalho foi verificado os possíveis impactos das variações climáticas no risco de queimadas no Brasil, com o uso do Modelo de Circulação Geral Acoplado OceanoAtmosfera ECHAM5/MPI-OM, em condições climáticas atuais e de aquecimento global. Para a validação dos resultados do ECHAM5 utilizou-se os dados de reanálises do NCEP. As análises climáticas, para os dados do ECHAM5 e NCEP, mostraram que o modelo representa relativamente bem o período atual em termos de temperatura, precipitação e umidade relativa. O ECHAM5 consegue capturar os padrões climatológicos dominantes, em particular sobre a região Amazônica. Sobre a região central do Brasil, o modelo tende a superestimar a temperatura e a precipitação, e subestimar a umidade relativa.
Com base nas análises do risco de queimadas propostos pelo Índice de Haines (IH), a partir de duas condições climáticas distintas, pode-se demonstrar que sob condições atuais as principais áreas de risco de queimadas concentram-se na região centro-oeste e norte do Brasil, com máxima atividade no mês de agosto. Para o final do século, em um cenário de aquecimento global, o IH apresenta áreas mais extensas com maiores valores no risco de queimadas.

Sabe-se que a maior parte das previsões das condições climáticas e atmosféricas devido às mudanças globais, são geradas pela extrapolação de estudos locais e de curta duração para cenários globais e de longo prazo. Estes são, todavia, fontes de incertezas e imprecisões. As interações dos elementos climáticos ocorrem de forma complexa e estão associadas as projeções dos diferentes modelos de circulação geral da atmosfera, que por sua vez diferem substancialmente nos seus resultados. Dependendo do cenário econômico usado (por exemplo: A2, A1B, B2, B1), as previsões de temperatura, precipitação e umidade variam tanto em magnitude como em suas distribuições espaciais. Logo, os resultados aqui apresentados são inteiramente dependentes dos campos atmosféricos anteriormente citados, e que estão também associados a incertezas.

Outro fato importante, é que as queimadas por serem de origem antrópica estão diretamente ligadas as atividades agroflorestais. Em adição, os fatores socioeconômicos e culturais atuais podem diferir completamente no futuro, fazendo com que apesar da atmosfera estar em condições de queima, o número de queimadas pode ser extremamente reduzido, devido às mudanças no nível antrôpico das queimadas. Por outro lado, 

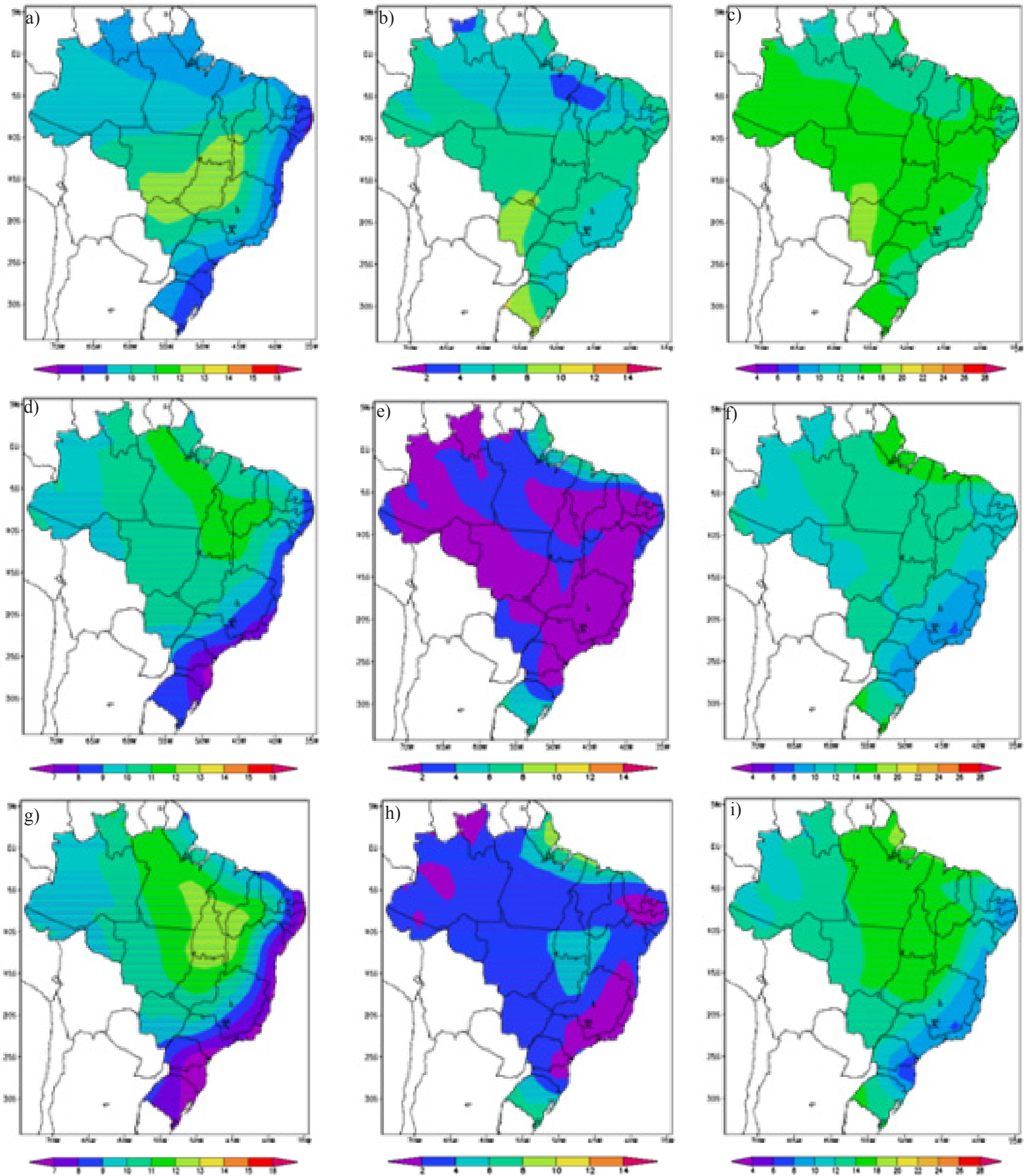

Figura 11 - Suscetibilidade do ambiente a ocorrências de queimadas do presente a partir dos dados do NCEP para o mês de outubro: a) Termo A, b) Termo B, c) Índice de Haines. Suscetibilidade do ambiente a ocorrências de queimadas do presente a partir dos dados do ECHAM para o mês de outubro: d) Termo A, e) Termo B, f) Índice de Haines. Suscetibilidade do ambiente a ocorrências de queimadas no futuro a partir dos dados do ECHAM para o mês de outubro: g) Termo A, h) Termo B, i) Índice de Haines. 
tem-se observado nos últimos anos uma maior incidência de raios, o que pode ocasionar no futuro um maior número de queimadas de origem natural.

\section{AGRADECIMENTOS}

Os autores agradecem o apoio da FAPEMIG para o desenvolvimento do presente artigo por meio convenio PPM00021 .

\section{REFERÊNCIAS BIBLIOGRÁFICAS}

ANDREAE, M.O., ATLAS, E., CACHIER, H., COFER, W.R., HARRIS, G.W., HELAS, G., KOPPMANN, R., LACAUX, J.-P., WARD, D.E. Trace gas and aerosol emissions from savanna fires. Biomass Burning and Global Change, edited by J.S. Levine, p. 278-295, 1996 a.

ANDREAE, M.O., ATLAS, E., HARRIS, G.W., HELAS, G., KOPPMANN, W., MANÕ, S., POLLOCK, W.H., RUDOLPH, J., SCHAEFFE, D., SCHEBESKE, G., WELLING, M.. Methyl halide emissions from savanna fires in Southem Africa. Journal Geophys Res., v. 101, p. 23603-23601, 1996 b.

ASLAN, Z., TOPÇU, S. Seasonal variation of surface fluxes and atmospheric interaction in Istanbul, Lisbon, Portugal. September, p. 22-27, 1994.

AZZALI, S.; MENENTI, M. Mapping vegetation-soil-climate complexes in Southern Africa using temporal fourier analysis of NOAA-AVHRR NDVI Data. International Journal of Remote Sensing, v.21, n.5, p.973-996, 2001.

BROTAK, T.L., REIFSNYDER, W.E. Predicing major wildfire occurrence. Fire Management Notes, v. 38, p. 5-8, 1977.

COOK, K., VIZY, E.K. Effects of Twenty-First-Century climate change on the Amazon rain forest. Journal of Climate, v. 21, n 3, p. 542-560, 2008.

COSTA, M.H., FOLEY, J.A. Combined effects of deforestation and doubled atmospheric $\mathrm{CO} 2$ concentrations on the climate of Amazonia. Journal of Climate, v. 13, p. 18-34, 2000.

COSTA, M.H., YANAGI, SILVIA N.M, SOUZA, P.J.O.P., RIBEIRO, A., ROCHA, E.J.P. Climate change in Amazonia caused by soybean cropland expansion, as compared to caused by pastureland expansion. Geophysical Research Letters, v. 34, p. L07706, 2007.

CRUTZEN, P.J., ANDREAE, M.O. Biomass burning in the tropics: impact on atmospheric chemistry and biogeochemical cycles. Science, v. 250, p. 1669-1678, 1990.

CRUZ, F.W., BURNS, S.J., KARMANN, I., SHARP, W.D., VUILlE, M., CARDOSO, A.O., FERRARI, J.A., DIAS, P.L.S., Jr, O.V. Insolation-driven changes in atmospheric circulation over the past 116,000 years in subtropical Brazil. Nature, v. 434, p. 63-66, 2005. doi: 10.1038/ nature 03365 .

EMERY, W., THOMSON, R. Data analysis methods in physical oceanography. Pergamon Press, Elsevier Science, Oxford, p. 643, 1997.

FERRAZ-VICENTINI, K.R. História do fogo no cerrado: uma análise palinológica. Tese de Doutorado, Universidade de Brasília, (DF), 1999.

GRIMM, A. M., NATORI, A. A. Climate change and interannual variability of precipitation in South America, Geophys. Res. Lett., 33, L19706, doi:10.1029/2006GL026821, 2006.

HAINES, D.A. A lower atmospheric severity index for wildland fires. Natl. Wea. Dig., v. 13, pp. 23-27, 1988.

HINES, K.M., BROMWICH, D.H., MARSHALL, G.J. Artificial surface pressure trends in the NCEP-NCAR reanalysis over the Southern Ocean and Antarctica. Journal of Climate v. 13, p. 3940-3952, 2000.

HINES, K.M., BROMWICH, D.H., MARSHALL, G.J. Artificial surface pressure trends in the NCEP-NCAR reanalysis over the Southern Ocean and Antarctica. Journal Climate v. 13, pp. 3940-3952, 2000.

JUNGCLAUS, J.H, KEENLYSIDE, N., BOTZET, M., HAAK, H., LUO, J.-J., LATIF, M., MAROTZKE, J., MIKOLAJEWICZ, U., ROECKNER, E. Ocean circulation and tropical variability in the coupled model ECHAM5/ MPI-OM, Journal of Climate, v. 19, p. 3952-3972, 2006.

JUSTINO, F.B, SOUZA, S.S., SETZER, A. Relação entre focos de calor e condições meteorológicas no Brasil. Anais do XII Congresso Brasileiro de Meteorologia. 2002.

JUSTINO, F.B. The influence of boundary conditions on the Last Glacial Maximum. Shaker Verlag, v. 127, p. 16, 2004.

KALNAY, E., KANAMISTU, M., KISTER, R., COLLINS, W., DEAN, D., GANDIN, L., IREDELL, M., SAHA, S. WHITE, G., WOOLLEN, J., ZHU, Y., CHELLIAN, M., EBISUZAKI, W., HIGGINS, W., JANOWIAK, J., MO, K.C., ROPELEWSKI. C., WANG. J., LEETMAN, A., REYNOLD, R., JENNE, R., JOSEPH, D. The NCEP/ NCAR 40-year reanalysis project. Bulletin of the American Meteorological Society, v.77, p.437-471, 1996.

KIRCHOFF, V. SCAR-B proceedings, Transec Editorial, INPE, São José dos Campos,(SP), p. 208, 1997.

LATURNER, N., SCHERER, H.W. As queimadas e os incêndios florestais em Mato Grosso. Revista Geonotas, v. 8, 2004.

LEMOS, C.F. O Índice de Haines como indicador de desenvolvimento de focos de calor no Brasil através do Modelo Regional Eta. Tese de Doutorado, Universidade Federal Fluminense, Rio de Janeiro, (RJ), 2006.

MARSLAND, S.J., HAAK, H., JUNGCLAUS, J.H., LATIF, M., RÖSKE, F. The Max Planck Institute global ocean/sea- 
ice model with orthogonal curvilinear coordinates. Ocean Modell, v. 5, p. 91-127, 2003.

PAGE, S.E., SIEGERT, F., RIELEY, J.O., BOEHM, H.-D.V., JAYA, A., LIMIN, S. The amount of carbon released from peat and forest fires in Indonesia during 1997. Nature, v.420, p.61-65, 2002.

PANOFSKY, H.A., BRIER, G.W. Some applications of statistics to meteorology. Pennsylvania. University Park, p. 224, 1968.

RIBEIRO, G.A., BONFIM, M,V.R. Incêndio florestal versus queima controlada. Revista Ação Ambiental, ano II, n 12, p. 8-11, 2000.

RIBEIRO, G.A.; SOARES, R.V. Caracterização do material combustível florestal e efeitos da queima controlada sobre sua redução em um povoamento de Eucalyptus viminalis. Cerne, Lavras, v. 4, n 1, p. 57-72, 1998.

SALDARRIAGA, J.G., WEST, D.C. Holocene fires in the northern amazon basin. Quaternary Research, v. 26, p. 358-366, 1986

SALGADO-LABOURIAU, M.L., FERRAZ-VICENTINI, K.R. Fire in the cerrado 32,000 years ago. Current Research in the Pleistocene, v. 11, p. 85-87, 1994.
SANFORD, R.L., SALDARRIAGA, J.G., CLARK, K.E., UHL, C., HERRERA, R. Science, p. 277-358, 1985.

SISMANOGLU, R.A., SETZER, A., JUSTINO, F., LIMA, W.F.A. Avaliação inicial do desempenho do risco de fogo gerado no CPTEC. Anais do XII Congresso Brasileiro de Meteorologia, 2002.

VERA, C., SILVESTRI, G., LIEBMANN, B., GONZALEZ, P. Climate change scenarios for seasonal precipitation in South America from IPCC-AR4 models. Geophysical Research Letters, v. 33, n 13, 2006. doi:10.1029/2006GL025759.

WILKS, D.S. Statistical methods in the atmospheric sciences: an introduction. San Diego, California, Academic Press, p. 467,1995

WINKLER, J.A., POTTER, B., WILHELM, D., SHADBOLT, R., BIAN, X., PIROMSOPA, K. A cimatology of the Haines Index for North America derived from NCEP/ NCAR reanalysis fields. Sixth Fire and Forest Meteorology Symposium, American Meteorological Society. 2005. 